\title{
Labor Unions, Unemployment, and Trade and Capital Liberalization
}

\author{
Doris Geide-Stevenson \\ Weber State University
}

\begin{abstract}
This paper utilizes a specific factor model where rewards to labor and capi tal, and employment are determined by efficient bargaining between entrepre neurs and workers in each sector. Union threat points arise endogenously since workers' outsi de opportunities in one sector depend on the bargain struck in the other sector. This fully unionized economy will generally be characterized by unemployment and inter-industry wage differentials. Both trade and capital liberalization may lead to an increase in overall employment. (JEL Classifications: F10, F 15, F 20, J51, J64) ४Key Words: Trade unions, Unemployment, Economic integration.>
\end{abstract}

\section{Introduction}

In countries that move toward integrating markets by liberalizing trade and capital movements, a preoccupation with the effects of these policies on the employment levels, or 'number of jobs' often dominates the public discussions. Traditional models of international trade theory, operating with a

\footnotetext{
* Correspondence Address: Weber State University, Department of E conomics, Ogden, UT 84408-3807, U.S.A. (Tel) 801-626-7634, (Fax) 801-626-7423, (E-mail) DGSTEVEN @ Weber.edu.
}

(C2000 - Center for International E conomics, Sejong Institution. All rights reserved. 
full-employment constraint, are not able to address these concerns about the effect of 'globalization' on unemployment which is modeled explicitly in the present paper. Since labor market institutions differ widely across countries, unemployment can be caused by various features in the labor market, such as minimum wages (Brecher [1974]), efficiency wages (Brecher/ Choudri [1994]), search (Davidson, [1988]), imperfect information (M atusz [1986]) and unionization. These features have been previously introduced in some form into the international trade literature. In the present paper unemployment arises because of unionization, a modeling approach particularly applicable to the E uropean Union where union membership is consistently higher and more significant for non-union members than in the United States (Freeman [1989]) with few signs of decline in the present (Wallerstein [1997]).

The present paper utilizes a specific factor model (Jones [1971]) with unemployment in order to study the effects of market integration on the overall employment level. Unemployment arises because of a collective bargaining process between entrepreneurs and workers in each of the two sectors that comprise the economy. Bargaining takes place on the industry level, between one industry union and a number of identical firms, and depends on bargaining outcomes in the other sector. The wage in the outside sector is important in helping to determine the fallback wage or the 'threat point' level in a Nash bargaining framework thus showing the influence of outside opportunities on sectoral wage setting. The model explicitly takes into account wage interdependence in unionized labor markets because unions care about other unions' wages. This idea has been previously studied and formalized by Flanagan [1976], Oswald [1979], Gylafson/ Lindbeck [1984], Pissarides [1985] and empirically validated by Lee/ Pesaran [1993]. Such a fully unionized economy will usually be characterized by both, unemployment and inter-industry wage differentials, that arise because of different union bargaining strengths, technologies, capital endowments, nominal output prices, and different outside opportunities available to capital in the two sectors. Katz/ Summers [1989] extensively document the existence of such inter-industry wage differentials even though workers are all equally productive and contend that "these wage differentials largely reflect rents earned by workers in high-wage industries". 
A paper by Laixun Zhao [1995] also analyzes international capital movements in the presence of union bargaining. He constructs a partial equilibrium model of intra-industry cross-hauling direct foreign investment and shows that the Nash products for the firm-union bargaining in the two countries become interdependent because two firms' profit functions enter the generalized Nash products simultaneously. In the present paper the interdependence of the $\mathrm{N}$ ash bargains comes from general equilibrium considerations in the labor market and applies to two sectors within one country.

Other recent contributions on the topic of labor unions and international trade include Brander/ Spencer [1988] and M ezetti/ Dinopolous [1991] who utilize frameworks that are more partial equilibrium in nature in order to study the effects of protection when imperfectly competitive firms are unionized. Their analysis is extended by Santoni [1996] to include more general assumptions about union bargaining and an extension to general equilibrium. Kemp/ vanLong/Shimomura [1991], Shimomura [1993], and B recher/ van Long [1989] model national unions within the two sector general equilibrium models used in international trade. Driffill/van der Ploeg [1993] study the effects of trade liberalization when unions have either a regional, national or international focus. These general equilibrium contributions focus on the monopoly union case. The present paper introduces efficient bargaining into a general equilibrium analysis, and models decentralized unions that are organized along industry lines. Such a model, compared to a model with national unions, applies better to the institutional structure which can be found, for example, in Germany where bargaining is characterized by "industry-level bargaining without participation of the peak level association" and "a labor agreement signed by the employer's association ... is binding for all affiliated firms regardless of the membership status of the firm's employees" (Wallerstein/ Golden/ Lange [1997]). The present model captures the stylized structure of a country characterized by high union coverage, but very decentralized decision-making.

After introducing the model, a short-run and long-run equilibrium will be discussed along with some comparative statics results on trade liberalization in each case. In a separate section international capital movements are considered. In a final section some numerical results illustrate the model. 


\section{Model}

The economy consists of two sectors $X$ and $Y$. Production in these sectors is characterized by a constant returns to scale technology. B oth sectors utilize capital and labor as inputs. While labor is assumed mobile between sectors, capital is sector specific; the fixed capital endowments $\mathrm{K}_{\mathrm{x}}$ and $\mathrm{K}_{\mathrm{y}}$ can only be employed in their respective sectors. Chiles/ Stewart [1993] show that the specificity of capital is a sufficient condition for a union wage premium. Since the present model assumes perfectly competitive product markets, the factor specificity can be thought of as justifying unionization in the first place. Let the constant returns to scale production functions be denoted by

$$
X=f\left(L_{x}, K_{x}\right) \quad Y=g\left(L_{y}, K_{y}\right) .
$$

The economy is assumed to be small and open which implies that the relative price of good $X$ in terms of $Y$ is fixed at the world price $p$. Thus, the setup corresponds to the standard two-good, three-factor model as analyzed by J ones [1971]. The present model differs in its description of factor markets, which are not assumed to be perfectly competitive. Instead, factor rewards to labor and capital and employment are determined by a collective bargaining process between entrepreneurs or employers' associations and workers in each sector. The capital owners are also the owners of firms. Workers can be thought of as being represented by unions which are organized along industry lines. In each sector the owners of the firm and workers bargain simultaneously over wages and employment. In modeling this bargaining procedure, the static, axiomatic approach, originated by Nash [1953] is followed. This approach only requires utility functions for the bargaining parties and a pair of utility levels that apply if agreement is not reached; here referred to as threat points, disagreement points or the fallback of the respective parties. Workers' utility is simply given as their wage level. The threat point of a union is determined by outside opportunities available to workers. In a partial equilibrium this is usually taken to be a wage rate $\bar{w}$ which can be obtained by working in a non-union firm where wages are determined via perfectly competitive markets. The wage rate $\bar{w}$ then represents real outside opportunities. This approach is, for example, taken by 
M CDonald and Solow [1981]. In the present general equilibrium model, a worker in sector $i$ can expect an average income of $e_{j} w_{j}, j=x, y$ and $j \neq i$, when negotiations with sector $\mathrm{i}$ employers break down. The probability of actually finding employment in sector $j$, the outside sector, is given by $e_{j} \in[0,1]$ implicitly assuming that at least some turnover occurs each bargaining period. There is also a probability of unemployment when bargaining breaks down. Here it is assumed that workers attach no utility to being unemployed. This assumption allows to write the disagreement point simply as $e_{j} w_{j} .{ }^{1}$ The union objective then is to maximize total union rents $L_{i}\left(w_{i}-e_{j} w_{j}\right)$ where any employee in the industry counts as a union member. The union is thus an open union as opposed to an insider dominated one. ${ }^{2}$ Capitalists' utility is given by their revenue net of labor cost. As there are no outside opportunities for the owners of sector specific capital, the effective threat point for capitalists is zero. Different bargaining strengths of the two sectoral unions are captured by the parameters $\alpha$ and $\beta, \alpha, \beta \in(0,1)$. The sectoral bargaining outcome is obtained by maximizing the generalized $N$ ash functions $F\left(w_{x}, L_{x}\right)$ and $G\left(w_{y}, L_{y}\right)$ with respect to $L_{i}$ and $w_{i}, i=x, y$.

$$
\begin{aligned}
& F=\left[L_{x}\left(w_{x}-e_{y} w_{y}\right)\right]\left[p f\left(L_{x}, K_{x}\right)-w_{x} L_{x}\right]^{1-} \\
& G=\left[L_{y}\left(w_{y}-e_{x} w_{x}\right)\right]\left[g\left(L_{y}, K_{y}\right)-w_{y} L_{y}\right]^{1-}
\end{aligned}
$$

$N$ ote that in this general equilibrium model the threat points for each union are determined endogenously and depend on the bargaining outcomes in the outside sector. This illustrates the idea that unions care about other unions' wages.

Initially it is assumed that the bargaining parties do not realize that they influence employment probabilities in the other sector, or the economy wide rate of unemployment. This assumption will be dropped in the following section. Unions in sector $\mathrm{i}$ are, however, aware that there is the possibility of

1. Layard and Nickell [1990] carefully model employer-union bargaining in a partial versus general equilibrium context and show that the 'outside opportunities' for unions are determined by a convex combination of employment at wage $\bar{w}$ and unemployment with benefit $\mathrm{B}$. In the present paper $\mathrm{B}$ is assumed to be zero. Layard and $\mathrm{N}$ ickell also explicitly model turnover.

2. For a discussion of theses different types of unions see Creedy/M cDonald [1991]. 
unemployment if $e_{j}<1$. Workers and firms take $e_{x}$ and $e_{y}$ as given. By this assumption, equations ( 3 ) and (4) are the first order conditions from maximizing (1) with respect to $w_{x}$ and $L_{x}$, when an interior or a 'boundary' solution with $L_{x} \leq \bar{L}-L_{y}$ can be obtained where $\bar{L}$ represents labor endowment.

$$
\begin{aligned}
& \left(p f\left(L_{x}, K_{x}\right)-w_{x} L_{x}\right)-(1-)\left(w_{x}-e_{y} w_{y}\right) L_{x}=0 \\
& w_{x}=p\left[\frac{F\left(L_{x}, K_{x}\right)}{L_{x}}+(1-) f_{L}\left(L_{x}, K_{x}\right)\right]
\end{aligned}
$$

Equation (4) states that the wage $\mathrm{w}_{\mathrm{x}}$ is a weighted average of workers' average product $f(.) / L_{x}$ and marginal product $f_{L}$ Since the average product exceeds the marginal product, wages are higher than they would be at the same employment level and under perfect competition. The larger the union's bargaining strength $\alpha$, the higher the weight attached to the average product will be. Equation (4) describes a downward-sloping curve in wage-employment space, referred to as the 'power locus' or Nash-B argaining Curve $\left(N B C_{x}\right)$ that lies above the marginal product curve $\mathrm{pf}_{\mathrm{L}}\left(\mathrm{K}_{x^{\prime}} \mathrm{L}_{\mathrm{x}}\right)$ (see figure 1).

Figure 1

Eguilibrium with Efficient B argaining-Unemployment Case

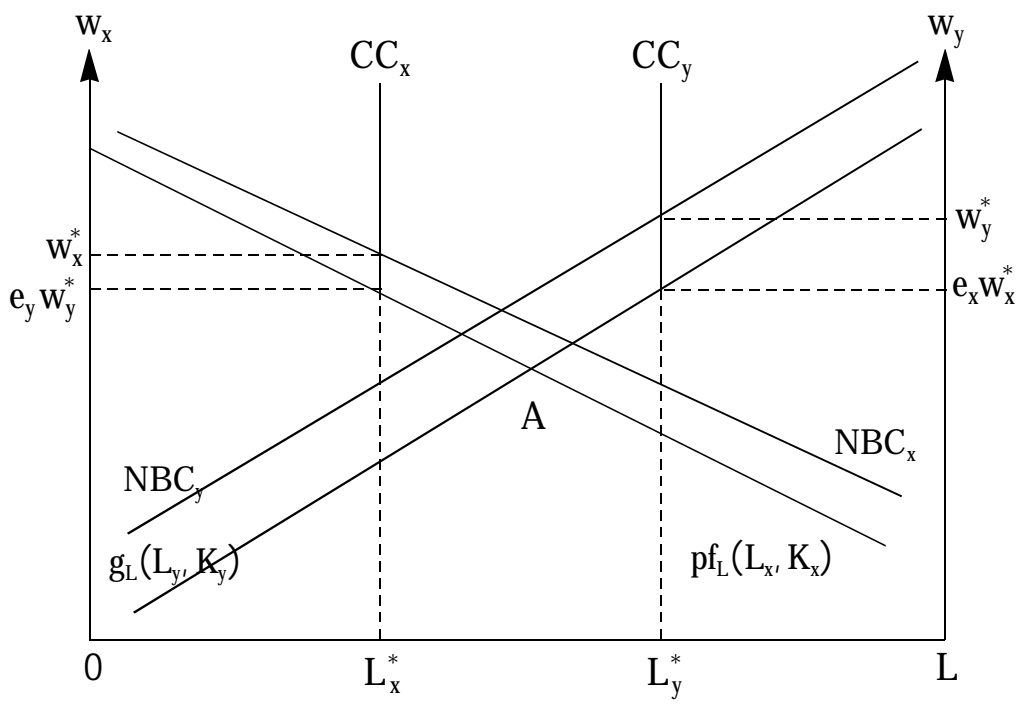


Similar first order conditions can be derived for sector $Y$ bargaining. Equations (5) and (6) emerge from maximizing $G$ with respect to $w_{y}$ and $L_{y}$ when $L_{y} \leq \bar{L}-L_{x}$.

$$
\begin{aligned}
& \left(g\left(L_{y}, K_{y}\right)-w_{y} L_{y}\right)-(1-)\left(w_{y}-e_{x} w_{x}\right) L_{y}=0 \\
& w_{y}=\left[\frac{g\left(L_{y}, K_{y}\right)}{L_{y}}+(1-) g_{L}\left(L_{y}, K_{y}\right)\right]
\end{aligned}
$$

Equation (6) is shown as $\mathrm{NBC}_{\mathrm{y}}$ in figure 1 , again lying above the sector $\mathrm{Y}$ marginal product curve $g_{L}\left(K_{y}, L_{y}\right)$.

Equations ( 3 ) and (4) together imply

$$
p f_{L}=e_{y} w_{y}
$$

and (5) and (6) imply

$$
g_{L}=e_{x} w_{x} .
$$

As workers' utility is assumed to be linear in the wage, under efficient bargaining the marginal product of labor in each sector is equated to the outside opportunities of workers. For example, for a given $e_{y} w_{y}$, determined by the bargaining outcomes in sector $Y$, sector $X$ employment is expanded until the marginal product $\mathrm{pf}_{\mathrm{L}}$ equals $e_{y} \mathrm{w}_{\mathrm{y}}$, the outside opportunity. This is illustrated in figure 1 where the horizontal axis represents the total labor endowment $\bar{L}$ for the economy. Employment in the $X$ sector is represented by the distance from the origin to $L_{x}^{*}$. Similarly, employment in the $Y$ sector is represented by the distance from $\bar{L}$ to $L_{y}^{*}$. For both sectors appropriate marginal product curves and $\mathrm{N}$ ash Bargaining Curves are shown. In a perfectly competitive economy, point $A$ denotes the fullemployment allocation of labor to the two sectors. Here, $L_{x}^{*}$ and $L_{y}^{*}$ are the general equilibrium employment levels with efficient bargaining and the distance between $L_{x}^{*}$ and $L_{y}^{*}$ shows the level of unemployment in the economy. Note that only outside opportunities determine the level of employment in each sector so that sectoral employment levels do not directly depend on own-sector wages, but on the wage and employment probability prevailing in the other sector. Once the employment level in one sector is determined, the NBC then illustrates the wage 
that workers will receive. In figure 1 , for an employment level $L_{x}^{*}$, workers receive the wage $W_{x}^{*}$ as determined by the intersection of the contract curve $C C_{x}$ and $N B C_{x}$. Here the contract curves (i.e. the locus of tangency points between the iso-profit and iso-utility curves) $\mathrm{CC}_{i}, i=x, y$ are vertically sloped in the wage-employment space, at the point where the marginal product of labor is equal to the workers' reservation wage $e_{j} w_{j}$. This follows from the assumption of linear utility. ${ }^{3}$ Changes in the exogenous variables $\alpha$ and $\beta$ shift the respective NBC while a change in $K_{x}, K_{y}$, and $p$ shifts both the respective sectoral marginal product curve and $N B C$. Together the hiring rules (7) and (8) describe an equilibrium that in general exhibits unemployment. The following sections differentiate between two cases, the 'short-run' where employment probabilities are taken to be exogenous and the 'longrun' where employment probabilities are endogenous.

\section{Short-run Equilibrium}

Assuming that the bargaining partners in each sector hold correct expectations concerning the outside wage and agree on expected employment probabilities, allows the derivation of two equilibrium conditions for sector $X$ and $Y$. Equations (9) and (10) are obtained by using the expressions for $w_{x}$ and $w_{y}$ from (4) and (6) in (7) and (8).

$$
\begin{aligned}
& p f_{L}\left(L_{x}, K_{x}\right)-e_{y}\left[\frac{g\left(L_{y}, K_{y}\right)}{L_{y}}+(1-) g_{L}\left(L_{y}, K_{y}\right)\right]=0 \\
& g_{L}\left(L_{y}, K_{y}\right)-e_{x}\left[p\left[\frac{f\left(L_{x}, K_{x}\right)}{L_{x}}+(1-) f_{L}\left(L_{x}, K_{x}\right)\right]\right]=0
\end{aligned}
$$

These two equations make explicit the idea that for given $e_{x}$ and $e_{y}$ sector $X$ employment is contingent on employment in sector $Y$, and vice versa. For example, should sector $X$ negotiate a higher wage $w_{X}$, because of an increase in the $X$ union power, say, then the $X$ sector employment is initially

3. I would like to thank an anonymous referee for suggesting the use of figure 1 to illustrate the model and for a clarification of the general equilibrium mechanism in this model. 
unaffected. Only $\mathrm{NBC}_{\mathrm{x}}$ shifts to the right, resulting in a higher wage $\mathrm{w}_{\mathrm{x}}$ at the same employment level $L_{x}^{*}$. However, this wage increase raises the outside opportunity for $\mathrm{Y}$-sector workers. The hiring rule (8) then implies reduced sector $Y$ employment and because the $N B C_{y}$ is downward-sloping, the sector $Y$ equilibrium wage increases at the same time. This drives up the outside opportunity for sector $X$ workers and decreases sector $X$ employment along with sector $Y$ employment. This illustrates the basic general equilibrium spillover of the model where own-sector employment does not directly depend on own-sector wages. This mechanism also explains why equations (9) and (10) trace out a positive relationship between sector $X$ and $Y$ employment with $\mathrm{dL}_{y} /\left.\mathrm{dL}_{\mathrm{x}}\right|_{x}>0$ for equation (9) and $\mathrm{dL}_{\mathrm{y}} /\left.\mathrm{dL}_{\mathrm{x}}\right|_{y}>0$ for (10). The Nash-equilibrium is stable when at equilibrium $\mathrm{dL}_{y} /\left.\mathrm{dL}_{\mathrm{x}}\right|_{\mathrm{x}}>$ $\mathrm{dL}_{y} /\left.\mathrm{dL}_{\mathrm{x}}\right|_{y}$, the slope of the equilibrium locus for sector $\mathrm{X}$ is larger than the slope for the $Y$ sector locus. This notion of stability implies that the simple dynamic adjustment process in which bargaining partners in the two sectors take turns myopically playing the best response to each others' current strategies, converges to the Nash equilibrium and allows to conduct comparative static exercises.

Figure 1 depicts a general equilibrium outcome with unemployment for such an economy. This unemployment case seems to be the more interesting case to study. It should be noted that the equilibrium described in figure 1 , is contingent on the employment probabilities assumed by the bargaining partners. Here the bargaining partners may observe that their expectations of $e_{i}$ do not materialize after bargaining actually takes place. The case where the expected employment probabilities are consistent with the bargaining outcomes will be discussed in the next section. This consistency condition will be associated with a long-run equilibrium. The following results are derived for the bargaining environment in which $e_{i}$ is taken as given by the firms and the unions. Such a model can be interpreted as a situation where firms and workers are not able to renegotiate even though they observe ex post that the bargaining was based on 'wrong' expectations about $\mathrm{e}_{\mathrm{i}}$.

Proposition 1: Both an increase in the expected employment probabilities for either sector and an increase in the bargaining strength of workers in either sector will reduce employment in sector $X$ and employment in sector 
$Y$, but will lead to higher wages in both sectors. (See the appendix for proof of the propositions)

Thus, optimistic expectations about the probability of employment in the outside sector and increased union bargaining strength will both lead to higher unemployment in the present model. A higher expected employment probability in the other sector drives up the opportunity cost of labor and therefore reduces employment. Optimism concerning employment on part of the bargaining parties will reduce actual employment in the economy. Increased union bargaining strength in one sector puts more weight on the average product of labor in wage negotiations, driving up wages and the threat point in the other sector. Either case leads to an increase in the unions' threat points.

Proposition 2 : Separate increases in capital endowments $K_{x}$ and $K_{y}$, and the world price $p$ have ambiguous effects on employment and wages in sectors $X$ and $Y$.

This result contrasts with the straightforward results from a standard specific factor model. The following example helps to illustrate the intuition behind proposition 2. As for example the capital stock in sector $X, K_{x}$ increases, both the marginal and average product of labor in sector $X$ increase. This shifts both $\mathrm{NBC}_{\mathrm{x}}$ (a weighted average of average and marginal product) and the marginal product curve $\mathrm{pf}_{\mathrm{L}}$ to the right. Initially, for given outside opportunities, sector $X$ employment and wages increase. For small increases in both $K_{x}$ and $L_{x}$, the wage equation (4) implies that the initial effect on $w_{x}$ is a higher average product with a constant marginal product since outside opportunities are fixed. ${ }^{4}$ This increase in $w_{x}$ will then also affect the threat point of the union in sector $Y$ which will negotiate a higher wage $w_{y}$ also, thus raising the threat point in $X$. If the threat point in $X$ increases sufficiently, it is possible that $L_{x}$ will actually fall after an increase in $\mathrm{K}_{\mathrm{x}}$. The standard specific factor model would predict a straightforward increase in sector $X$ employment. In the present model similar arguments apply to changes in $K_{y}$ and $p$. However, it can be ruled out that 'perverse'

4. This follows from the fact that the total output elasticity from a change in $L$ and $K$ exceeds the output elasticity of labor, thus increasing the average product. 
effects occur as long as the short-run equilibrium is unique and stable. For example, an increase in $p$, due to efforts to protect sector $X$, will never decrease $L_{x}$ and at the same time increase $L_{y}$, and in effect reverse the intended effect of protection. But, it is possible that protection of one sector, say $X$, may lead to a higher overall unemployment rate by lowering employment either in both sectors or by reducing sector $Y$ employment by more than the increase in sector $X$ employment.

\section{Long-run Equilibrium}

In the previous discussion the employment probabilities $e_{1}, i=x, y$, do not have to be consistent with the actual sectoral employment probabilities $L_{i}^{*} /\left(\bar{L}-L_{j}^{*}\right)$. The actual employment probability in sector $\mathrm{i}$ is modeled as the ratio of the number of workers employed in sector $i$ in relation to all workers in the economy that are not employed in sector $\mathrm{j}, L-L_{j}^{*}$. M odeling the employment probabilities in such a fashion suggests that all the workers not employed in industry $\mathrm{j}$ have an equal chance of getting a job in industry i. A union in the present model thus represents all workers in the economy that are cur rently not employed in another sector and does not differentiate between employed and unemployed workers. This bargaining process also implies complete turnover during each bargaining period.

In the current context the long-run equilibrium is defined as the $N$ ash equilibrium $\left(L_{x}^{*}, L_{y}^{*}\right)$, so that

$$
e_{x}=L_{x}^{*} /\left(\bar{L}-L_{y}^{*}\right)=\tilde{e}_{x} \quad \text { and } \quad e_{y}=L_{y}^{*} /\left(\bar{L}-L_{x}^{*}\right)=\tilde{e}_{y}
$$

where $\tilde{e}_{x}$ and $\tilde{e}_{y}$ are such that they are consistent with the expected employment opportunities. In the short-run, derived above, it is likely that the expected employment probabilities do not match the actually observed employment opportunities in the economy. With $e_{x} \neq \tilde{e}_{x}$, and/ or $e_{y} \neq \tilde{e}_{y}$, the bargaining parties have an incentive to renegotiate until condition (11) is met where expected and actual probabilities do not diverge any longer. Using (9), (10) and (11), the equilibrium conditions for the long-run are: 


$$
\begin{aligned}
& p f_{L}\left(L_{x}^{*}, K_{x}\right)-\frac{L_{y}^{*}}{\bar{L}-L_{x}^{*}}\left[\frac{g\left(L_{y}^{*}, K_{y}\right)}{L_{y}^{*}}+(1-) g_{L}\left(L_{y}^{*}, K_{y}\right)\right]=0 \\
& g_{L}\left(L_{y}^{*}, K_{y}\right)-\frac{L_{x}^{*}}{\bar{L}-L_{y}^{*}}\left[p\left[\frac{f\left(L_{x}^{*}, K_{x}\right)}{L_{x}^{*}}+(1-) f_{L}\left(L_{x}^{*}, K_{x}\right)\right]\right]=0
\end{aligned}
$$

In order to study comparative statics effects of changes in the exogenous variables $\alpha, \beta, \bar{L}, K_{x}, K_{y}$ and $p$ on the equilibrium system (12) and (13), again the stability condition $\mathrm{dL}_{y}^{*} /\left.\mathrm{dL}_{\mathrm{x}}^{*}\right|_{\mathrm{x}}>\mathrm{dL}_{\mathrm{y}}^{*} /\left.\mathrm{dL}_{\mathrm{x}}^{*}\right|_{y}$ is assumed to hold.

\section{A. Comparative Statics - E mployment E ffects}

Comparative statics effects of changes in the exogenous variables $\alpha, \beta, \bar{L}$, $\mathrm{K}_{\mathrm{x}}, \mathrm{K}_{\mathrm{y}}$, and $\mathrm{p}$ depend on the sign of $\tilde{a}_{12}$ for employment in sector $\mathrm{X}$ and on the sign of $\tilde{a}_{21}$ for employment in sector $\mathrm{Y}$.

Proposition 3: Summary of Results

\begin{tabular}{|c|c|c|c|c|}
\hline & $\mathrm{dL}_{\mathrm{x}}$ & $\mathrm{dL}_{\mathrm{x}}$ & $\mathrm{dL}_{\mathrm{y}}$ & $\mathrm{dL}_{\mathrm{y}}$ \\
\hline & $\tilde{a}_{12}>0$ & $\tilde{a}_{12}<0$ & $\tilde{a}_{21}>0$ & $\tilde{a}_{21}<0$ \\
\hline $\mathrm{dK}_{\mathrm{x}}$ & $?$ & positive & $?$ & negative \\
\hline $\mathrm{dK}_{\mathrm{y}}$ & $?$ & negative & $?$ & positive \\
\hline$d \bar{L}$ & positive & $?$ & positive & $?$ \\
\hline $\mathrm{dp}$ & $?$ & positive & $?$ & negative \\
\hline $\mathrm{d} \alpha$ & negative & positive & negative & negative \\
\hline $\mathrm{d} \beta$ & negative & negative & negative & positive \\
\hline
\end{tabular}

The results require a discussion of the determinants of the sign of $\tilde{a}_{21}$ and $\tilde{a}_{12}$. Here, only $\tilde{a}_{12}$ will be looked at. A parallel discussion holds for the term $\tilde{a}_{21}$. The term is found in the Jacobian matrix and denotes the change in the expected outside wage for a sector $X$ worker when employment in sector $Y$ changes. This expected outside wage changes with $L_{y}$ because of a concomitant change in sector $Y$ wages and the employment probability, thus changing outside opportunities for sector $X$ workers. 


$$
\tilde{a}_{12}=\frac{\left(-e_{y} w_{y}\right)}{L_{y}}=-\frac{1}{\bar{L}-L_{x}}\left(w_{y}+\frac{w_{y}}{L_{y}} L_{y}\right) .
$$

Define

$$
=-\frac{L_{y}}{w_{y}} \frac{w_{y}}{L_{y}}
$$

where $\varepsilon_{y}$ denotes the employment elasticity of labor in sector $Y$. N ote that this elasticity is derived from equation (6) only and thus describes a measure of the slope of the $\mathrm{NBC}_{y}$, but is not a general equilibrium concept. For

$$
\begin{aligned}
& { }_{y}>1 \Rightarrow \tilde{a}_{12}<0 \\
& { }_{y}<1 \Rightarrow \tilde{a}_{12}>0 .
\end{aligned}
$$

The impact of the magnitude of this elasticity on the comparative static results can be demonstrated as follows. For example, consider an increase in the capital stock $\mathrm{K}_{\mathrm{x}^{\prime}}$. As discussed in the context of proposition 2, the initial adjustments in the economy will be as follows. A higher $\mathrm{K}_{\mathrm{x}}$ will put upward pressure on $w_{x}$, as the average product in sector $X$ increases. This increases the threat point of sector $Y$ workers and leads to an upward adjustment of sector $Y$ wages and a lowering of sector $Y$ employment. The sign of $\varepsilon_{y}$ determines the subsequent effect on the threat point of sector $X$ workers. With $\varepsilon_{y}>1$, the effect of lowering employment opportunities in sector $Y$ dominates the effect of an increased $w_{y}$, thus lowering the threat point for sector $X$ workers. With that, an increase in $K_{x}$ will unambiguously increase employment in the $X$ sector. With $\varepsilon_{y}<1$, the threat point for sector $X$ workers will be driven up, opening up the possibility of reduced employment in sector $X$ in response to a higher capital stock. In summary, with $\varepsilon_{y}<(>) 1$, the threat point for workers in sector $X$ increases (decreases) in response to lower (higher) employment in $\mathrm{Y}$.

As long as employment in both sectors is elastic with respect to wages, the comparative statics results are identical to the results obtained within the specific sector model. If the sector specific capital stock increases, then employment in this sector will increase. An increase in the relative price of good $X$ will lead to expanded employment in sector $X$ and lower employ- 
ment in sector $Y$. Only the ambiguity of a change in the labor endowment warrants an explanation. An increase in $\bar{L}$ will initially impact on the employment probabilities leading to an expansion of employment and lower wages in both sectors. With $a_{i j}>0$, the wage effect on the threat points dominates thus leading to higher $L_{x}$ and $L_{y}$. With $a_{i j}<0$, the employment effects on the threat points dominate opening up the possibility of reduced employment.

It is interesting to note that the effect of changes in the union bargaining strength on own-sector employment changes with the employment elasticities. For example, an increase in bargaining power for the union in sector $X$ leads to higher employment only when the threat point is lowered because of a lower employment probability outside sector $X$, i.e., when employment in sector $Y$ reacts elastically to own-sector wage changes. This result again emphasizes the intersectoral interdependence and shows that the general equilibrium context requires unions to be aware of employment elasticities in outside sectors as well as their own sector.

\section{B. Comparative Statics - Wages, Labor E arnings, Profits}

In this paragraph only the elastic case $\tilde{a}_{12}, \tilde{a}_{21}<0$ will be considered. While the results for sectoral employment changes in this case are clear, the effects of changes in the exogenous variables $\alpha, \beta, K_{x}, K_{y}, p$ and $\bar{L}$ on the sectoral wages are for the most part ambiguous. Clear predictions can only be made for sector $X(Y)$ wages when changes concerning sector $Y(X)$ are considered. For example, an increase in sector $X$ capital $K_{x}$ will increase wages paid to sector $Y$ workers because employment effects dominate wage effects, the threat point for sector $Y$ workers increases, lowering $Y$ employment, which implies a higher wage $w_{y}$. Similarly, $\partial w_{x} / \partial K_{y}>0$,

$$
w_{y} />0, w_{x} />0 \text {, and } w_{y} / p>0 .
$$

However, clear results can be obtained concerning sectoral labor earnings and sectoral revenue. These results are summarized in the following proposition. 


\section{Proposition 4 :}

\begin{tabular}{|c|c|c|c|c|}
\hline & $d\left(w_{x} L_{x}\right)$ & $d\left(w_{y} L_{y}\right)$ & $d\left(p f\left(L_{x}, K_{x}\right)\right.$ & $d\left(g\left(L_{y^{\prime}} K_{y}\right)\right.$ \\
\hline $\mathrm{dK}_{\mathrm{x}}$ & $>0$ & $<0$ & $>0$ & $<0$ \\
\hline$d K_{y}$ & $<0$ & $>0$ & $<0$ & $>0$ \\
\hline$d p$ & $>0$ & $<0$ & $>0$ & $<0$ \\
\hline$d \alpha$ & $>0$ & $<0$ & $>0$ & $<0$ \\
\hline$d \beta$ & $<0$ & $>0$ & $<0$ & $>0$ \\
\hline
\end{tabular}

Note that sectoral labor earnings and sectoral revenue always move in the same direction. Thus, the effects of changes in the exogenous variables on sectoral profits cannot be determined.

\section{Liberalizing Capital Mobility}

Allowing capital to move internationally introduces positive outside opportunities for capital. Denoting these opportunities with $R_{x}$ and $R_{y}$ changes the bargaining functions to

$$
\begin{aligned}
& F=\left[L_{x}\left(w_{x}-e_{y} w_{y}\right)\right]\left[p f\left(L_{x}, K_{x}\right)-w_{x} L_{x}-R_{x}\right]^{1-} \\
& G=\left[L_{y}\left(w_{y}-e_{x} w_{x}\right)\right]\left[g\left(L_{y}, K_{y}\right)-w_{y} L_{y}-R_{y}\right]^{1-}
\end{aligned}
$$

The wage equations change to

$$
\begin{aligned}
& w_{x}^{\prime}=p\left[\frac{f\left(L_{x}, K_{x}\right)}{L_{x}}+(1-) f_{L}\left(L_{x}, K_{x}\right)\right]-\frac{R_{x}}{L_{x}} \\
& w_{y}^{\prime}=\left[\frac{g\left(L_{y}, K_{y}\right)}{L_{y}}+(1-) g_{L}\left(L_{y}, K_{y}\right)\right]-\frac{R_{y}}{L_{y}}
\end{aligned}
$$

Equations (16) and (17) imply that for a given employment level, wages will be lower, the higher the outside opportunities of capital. N ow, wages are a weighted average of marginal product and average product net of capital's outside opportunities. M aximizing (14) and (15) with respect to wages and employment still implies the hiring rules. 


$$
p f_{L}=e_{y} w_{y}^{\prime} \text { and } g_{L}=e_{x} w_{x}^{\prime} .
$$

In the case where domestic returns to capital exceed the returns which can be earned elsewhere, capital inflows will be observed (if other countries are not characterized by the same collective bargaining agreement). The comparative statics results from propositions 3 and 4 apply here and indicate that capital inflows in sector i will lead to higher employment and higher labor earnings in sector $\mathrm{i}$, while sector $\mathrm{j}$ employment will decline along with labor earnings (for $\tilde{a}_{i j}<0$ ). The effects on sectoral profits cannot be predicted.

Proposition 5: In the short-run, an increase in $\mathrm{R}_{\mathrm{x}}$ or $\mathrm{R}_{\mathrm{y}}$ increases employment in both sectors. In the long-run, an increase in capital's outside opportunities in sector $\mathrm{i}$ will increase employment in sector $\mathrm{j}$ only. Own-sector employment will fall (increase) if $\tilde{a}_{i j}<0\left(\tilde{a}_{i j}>0\right)$.

In the short-run, an increase in $R_{i}$ reduces wages in sector $i$ and the threat point for labor in sector $\mathrm{j}$, thus both sectors expand employment. In the long-run both sectors will expand employment only if the wage effect on the threat point exceeds the employment ef fect, i.e. if $\tilde{a}_{i j}>0$.

\section{Numerical Examples}

An important feature of the present model is that generally the economy will be characterized by inter-industry wage differentials. These sectoral wage differences emerge because of differences in union bargaining strength, technologies, capital endowment, different nominal prices for the goods $X$ and $Y$, and different outside opportunities available to capital in the two sectors. First, a completely symmetric benchmark case (case 1 ) will be set up. Cases 2 and 3 will be used to demonstrate which factors can cause one sector to become a high-wage sector.

Case 1: Production functions: $f\left(K_{x}, L_{x}\right)=K_{x}^{0.5} L_{x}^{0.5}, g\left(K_{y}, L_{y}\right)=K_{y}^{0.5} L_{y}^{0.5}$.

Parameter values: $K_{x}=K_{y}=\bar{L}=10, \quad==0.5, p=1 \quad R_{x}=R_{y}=0$.

The results are $L_{x}=L_{y}=4, w_{x}=w_{y}=1.18585$. 
Case 2: Production functions: $f\left(K_{x}, L_{x}\right)=K_{x}^{0.5} L_{x}^{0.5}, g\left(K_{y}, L_{y}\right)=K_{y}^{0.3} L_{y}^{0.7}$.

Parameter values: $K_{x}=K_{y}=\bar{L}=10, \quad==0.5, p=1 \quad R_{x}=R_{y}=0$.

The results are $L_{x}=3.79938, L_{y}=4.72575, w_{x}=1.21676$, and $w_{y}=1.06433$.

Case 3: Production functions: $f\left(K_{x}, L_{x}\right)=K_{x}^{0.5} L_{x}^{0.5}, g\left(K_{y}, L_{y}\right)=K_{y}^{0.5} L_{y}^{0.5}$.

Parameter values: $K_{x}=K_{y}=\bar{L}=10, \quad==0.5, p=1, R_{x}=0.5, R_{y}=0.6$.

The results are $L_{x}=4.17533, L_{y}=4.1081, w_{x}=1.10081$, and $w_{y}=1.09712$.

Case 2 is an example of increased labor productivity in sector $Y$ relative to sector $X$. The change compared to case 1 is technology driven. The output elasticity of labor in sector $Y$ is higher than compared to the benchmark case. The effects are as follows. Increased sector $Y$ labor productivity initially pushes the marginal product above the outside opportunities of labor and leads to more hiring. As sector $Y$ employment expands, the threat point for sector $X$ workers increases, causing lower sector $X$ employment, but a higher $w_{x}$. The effect on sector $Y$ wages cannot be determined theoretically, as higher employment and higher productivity are opposing effects. In case 2 , $w_{y}$ actually falls. Thus increased labor productivity in sector $Y$ will turn sector $X$ into the high-wage sector. In the present model the availability of good outside opportunities, not own-sector productivity, determines the highwage sector.

The effect of either decreased union bargaining power or increased outside opportunities for capital (as demonstrated in case 3) work towards directly reducing own-sector wages relative to wages earned elsewhere. Both, a strong union or a low threat point for capital in one sector, will increase own-sector wages and create a high-wage sector.

Considering a change in the output price $p$, driven, for example, by an increase of the tariff on an import competing good, can lead to a total drop in employment in the type of economy considered above. Thus, protection from trade for one sector can have an adverse effect on economy-wide employment. In contrast, increased outside opportunities available to capital can lead to an expansion in total employment. In this bargaining model, increased outside opportunities for capital will not lead to actual international capital movements. Instead, the domestic bargaining position of firms improves, allowing a negotiation of wage concessions so that capital is able 
to earn higher returns without actually relocating. ${ }^{5}$

\section{Conclusion}

The major results in this paper are driven by a special general equilibrium spillover between the two sectors of the economy where one union's disagreement point is modeled as expected wages that can be earned at least temporarily, should bargaining break down, in the alternative sector. Often this disagreement point is not considered to be identical to the 'outside option' available to an agent, but is seen to represent the utility workers achieve during a strike without entering alternative employment, for example (see Binmore et. al. [1986]). Then the appropriate disagreement point are strike funds paid by the union or the utility attached to leisure. With this view of the disagreement point, the general equilibrium spillover in the model considered above would not exist, effectively insulating the two sectors from each other.

Given the special sectoral interdependence considered above, the present paper demonstrates that both trade liberalization and liberalization of international capital movements have the potential to increase employment in an economy where unemployment is caused by union bargaining in a fully unionized economy. Capital liberalization improves the outside opportunities available to capital so that capital's threat point increases which leads to lower wages and higher employment. In this model, increased outside opportunities for capital will not lead to actual international capital movements, but help to elicit bargaining concessions from labor unions. In terms of trade policy, results indicate that protection of the high-wage sector via an import tariff might lead to higher unemployment for the economy. While protection of the high-wage industry succeeds in expanding employment and increasing wages for this industr $y$, the special sectoral interdependence leads to a decline in employment in the low-wage sector which opens up the possibility of higher overall unemployment.

5. Specific examples are available upon request. 


\section{References}

Binmore, Ken, Ariel Rubinstein and Asher Wolinsky [1986], "The Nash Bargaining Solution in E conomic M odelling," Rand Journal of E conomics 17; pp. 176-188.

Brander, James and Barbara Spencer [1988], "Unionized Oligopoly and International Trade Policy," Journal of International Economics 24; pp. 217-234.

Brecher, Richard [1974], "M inimum Wage Rates and the Pure Theory of International Trade," Quarterly Journal of E conomics 88; pp. 98-116.

B recher, Richard and Ehsan Choudri [1994], "Pareto Gains from Trade, Reconsidered," Journal of International E conomics 36; pp. 223-238.

B recher, Richard and Ngo Van Long [1989], "Trade Unions in an Open Economy: A General Equilibrium Analysis," Economic Record 65; pp. 234-239.

Chiles, Ted and James Stewart [1993], "Union Rent Appropriation and Ex Post Analysis," Journal of Labor Research 14; pp. 317-333.

Creedy, J ohn and Ian M cD onald [1991], "M odels of Trade U nion B ehavior:

A Synthesis," Economic Record 67; pp. 346-359.

Davidson, Carl, Lawrence M artin and Steven M atusz [1988], “The Structure of Simple General Equilibrium Models with Frictional Unemployment," Journal of Political E conomy 96; pp. 1267-1293.

Drifill, J ohn and Frederick van der Ploeg [1993], "M onopoly U nions and the Liberalisation of International Trade," E conomic Journal 103; pp. 385379.

Flanagan, Robert [1976], "Wage Interdependence in Unionized Labor M arkets," Brookings Papers on E conomic Activity 3; pp. 635-673.

Freeman, Richard [1989], "On the Divergence in Unionism among Developed Countries," NBER Working Paper No. 2817.

Gylfason, Thorvaldur and Assar Lindbeck [1984], "Union Rivalry and Wages: An Oligopolistic Approach," E conomica 51; pp. 129-139.

Jones, Ronald [1971], "A Three-F actor M odel in Theory, Trade, and History," in J. Bhagwati et.al. (eds.), Trade, Balance of Payments, and Growth, Amsterdam: North-Holland.

Katz, Lawrence and Lawrence Summers [1989], "Can Interindustry Wage 
Differentials J ustify Strategic Trade Policy," in R. Feenstra (ed.). Trade Policies for International Competitiveness, Chicago and London: The Chicago University Press.

Kemp, M urray, Ngo Van Long and Kazuo Shimomura [1991], Labour Unions and the Theory of International Trade, Amsterdam: N orth-Holland.

Layard, Richard and Stephen Nickell [1990], "Is U nemployment Lower if Unions Bargain over Employment," Quarterly Journal of Economics 105; pp. 773-757.

Lee, Kevin and Hashem Pesaran [1993], "The Role of Sectoral Interactions in Wage Determination in the UK Economy," Economic Journal 103; pp. 21-55.

M atusz, Steven [1986], "Implicit Contract, Unemployment and International Trade," Economic Journal 96; pp. 307-322.

M CD onald, Ian and Robert Solow [1981], "Wage Bargain and Employment," American E conomic Review 71; pp. 896-908.

M ezzetti, Claudio and Elias Dinopoulos [1991], "Domestic Unionization and Import Competition," Journal of International Economics 31; pp. 79 100.

Nash, J ohn [1953], "Two-Person Cooperative Games," E conometrica 21; pp. 128-140.

Oswald, Andrew [1979], "Wage Determination in an Economy with M any Unions," Oxford E conomic Papers 31; pp. 369-385.

Oswald, Andrew [1985], "Trade unions, An Introductory Survey," Scandina vian Journal of Economics 87; pp. 160-193.

Pissarides, Christopher [1985], "Dynamics of Unemployment, Vacancies and Real Wages with Trade Unions," Scandinavian Journal of Econom ics 87; pp. 386-403.

Santoni, M ichele [1996], “Union-Oligopoly Sequential Bargaining: Trade and Industrial Policies," Oxford E conomic Papers 48; pp. 640-663.

Shimomura, Kazuo [1993], "Essays on the Economic Analysis of Labour Unions," Kobe Research Institute for Economics and Business Adminis tration.

Wallerstein, M ichael, M iriam Golden and Peter Lange [1997], "Unions, Employers' Associations, and Wage-Setting Institutions in Northern 
and Central Europe 1950-1992," Industrial and Labor Relations Review 50; pp. 379-401.

Zhao, Laixun [1995], "Cross-hauling Direct Foreign Investment and Unionized Oligopoly," European Economic Review 39; pp. 1237-1253.

\section{Appendix}

Totally differentiating (7) and (8) yields:

$$
\begin{aligned}
& {\left[\begin{array}{ccc}
p f_{L L} & -e_{y}\left(w_{y} / L_{y}\right) & \left\lceil d L_{x}\right. \\
-e_{x}\left(w_{x} / L_{x}\right) & g_{L L}
\end{array}\right]=}
\end{aligned}
$$

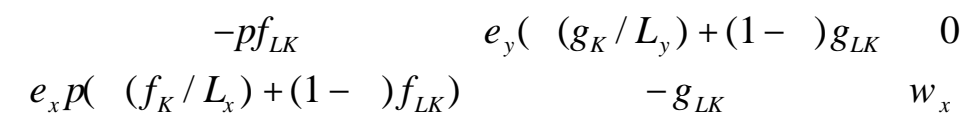

$$
\begin{aligned}
& \left.0 \quad e_{y}\left(\left(g / L_{y}\right)-g_{L}\right)-f_{L}\right\rceil \\
& \left.e_{x} p\left(\left(f / L_{x}\right)-f_{L}\right) \quad 0 \quad A\right] \\
& x\left[d K_{x}, d K_{y}, d e_{x}, d e_{y}, d \alpha, d \beta, d p\right]^{\top} . \\
& A=e_{x}\left(\alpha\left(f / L_{x}\right)+(1-\alpha) f_{x}\right)
\end{aligned}
$$

The partial derivatives $\partial \mathrm{w}_{\mathrm{i}} / \partial \mathrm{L}_{\mathrm{i}}$ can be signed as follows:

$$
\begin{aligned}
& w_{x} / L_{x}=p\left(\left(/ L_{x}\right)\left(f_{L}-f / L_{x}\right)+(1-\quad) f_{L L}\right)<0 . \\
& \left.w_{y} / L_{y}=\left(\quad / L_{y}\right)\left(g_{L}-g / L_{y}\right)+(1-\quad) g_{L L}\right)<0
\end{aligned}
$$

The assumption of stability of the Nash equilibrium $\mathrm{dL}_{y} /\left.\mathrm{dL}_{x}\right|_{x}>\mathrm{dL}_{y} /\left.\mathrm{dL}_{x}\right|_{y}$ allows to sign the Jacobian of system (7) and (8) with $|J|>0$, with

$$
d L_{y} /\left.d L_{x}\right|_{x}=\frac{p f_{L L}}{e_{y}\left(w_{y} / L_{y}\right)}>d L_{y} /\left.d L_{x}\right|_{y}=\frac{e_{x}\left(w_{x} / L_{x}\right)}{g_{L L}}
$$

This assumption allows to draw figure 1. Comparative statics are conducted by applying Cramer's Rule. 


\section{Proof of Proposition 1:}

$\frac{d L_{x}}{d e_{x}}=\frac{1}{J}\left(e_{y}\left(w_{y} / L_{y}\right) w_{x}<0, \frac{d L_{y}}{d e_{x}}=\frac{1}{J}\left(p f_{L L} w_{x}\right)<0\right.$

$\frac{d L_{x}}{d e_{y}}=\frac{1}{J}\left(g_{L L} w_{y}\right)<0, \frac{d L_{y}}{d e_{y}}=\frac{1}{J}\left(e_{x}\left(w_{x} / L_{x}\right) w_{y}<0\right.$

$\frac{d L_{x}}{d}=\frac{1}{J}\left(e_{y}\left(w_{y} / L_{y}\right) e_{x} p\left(f / L_{x}-f_{L}\right)\right)<0 \frac{d L_{y}}{d}=\frac{1}{J}\left(e_{x} p^{2} f_{L L}\left(f / L_{x}-f_{L}\right)\right)<0$

$\frac{d L_{y}}{d}=\frac{1}{J}\left(e_{x}\left(w_{x} / L_{x}\right) e_{y}\left(g / L_{y}-g_{L}\right)\right)<0, \frac{d L_{x}}{d}=\frac{1}{J}\left(g_{L L} e_{y}\left(g / L_{y}-g_{L}\right)\right)<0$.

\section{Proof of Proposition 2:}

$\frac{d L_{x}}{d K_{x}}=\frac{1}{J}\left(e_{x} e_{y} p\left(f_{K} / L_{x}+(1-) f_{L K}\right)\left(w_{y} / L_{y}\right)-p f_{L K} g_{L L}\right)<(>) 0$

$\frac{d L_{x}}{d K_{y}}=\frac{1}{J}\left(e_{y}\left(g_{K} / L_{y}+(1-) g_{L K}\right) g_{L L}-e_{y}\left(w_{y} / L_{y}\right) g_{L K}\right)<(>) 0$

$\frac{d L_{y}}{d K_{y}}=\frac{1}{J}\left(e_{x} e_{y}\left(g_{K} / L_{x}+(1-) g_{L K}\right)\left(w_{x} / L_{x}\right)-p f_{L L} g_{L K}\right)<(>) 0$

$\frac{d L_{y}}{d K_{x}}=\frac{1}{J}\left(e_{y} p^{2}\left(f_{K} / L_{x}+(1-\quad) f_{L K}\right) f_{L L}-e_{x}\left(w_{x} / L_{x}\right) p f_{L K}\right)<(>) 0$

$\frac{d L_{x}}{d p}=\frac{1}{J}\left(e_{x} e_{y}\left(f / L_{x}+(1-) f_{L}\right)\left(w_{y} / L_{y}\right)-f_{L} g_{L L}\right)<(>) 0$

$\frac{d L_{y}}{d p}=\frac{1}{J}\left(e_{x}\left(f_{K} / L_{x}+(1-) f_{L}\right) p f_{L L}-f_{L} e_{x}\left(w_{x} / L_{x}\right)<(>) 0\right.$

\section{Proof of Proposition 3:}

Totally differentiating ( $\left.7^{\prime}\right)$ and $\left(8^{\prime}\right)$ yields the following system:

$$
[\tilde{J}]\left[d L_{x}\right\rceil\left[L_{y}\right\rfloor=\left[\begin{array}{ccccc}
-p f_{L K} & e_{y} B-\frac{L_{y}}{\left(\bar{L}-L_{x}\right)^{2}} w_{y} & -f_{x} & 0 & e_{y} C \\
e_{y} D & g_{L K}-\frac{L_{x}}{\left(\bar{L}-L_{y}\right)^{2}} w_{x} & e_{x} E & e_{x} F & 0
\end{array}\right]
$$




$$
\begin{aligned}
& B=\left(g_{K} / L_{y}\right)+(1-) g_{L K}>0 \\
& C=\left(g / L_{y}-g_{L}\right)>0 \\
& D=p\left(\left(f_{K} / L_{x}\right)+(1-) f_{L K}\right)>0 \\
& E=\left(f / L_{x}\right)+(-) f_{L}>0 \\
& F=p\left(f / L_{x}-f_{L}\right)>0
\end{aligned}
$$

where $[\tilde{J}]=\left[\begin{array}{ll}\tilde{a}_{11} & \tilde{a}_{12} \\ \tilde{a}_{21} & \tilde{a}_{22}\end{array}\right]$

with

$$
\begin{aligned}
& \tilde{a}_{11}=p f_{L L}-\left(L_{y} /\left(\bar{L}-L_{x}\right)^{2}\right) w_{y}<0 \\
& \left.\tilde{a}_{12}=-\left(1 / \bar{L}-L_{x}\right)\right)\left(w_{y}+L_{y}\left(w_{y} / L_{y}\right)\right)<(>) 0 \\
& \left.\tilde{a}_{21}=-\left(1 / \bar{L}-L_{y}\right)\right)\left(w_{x}+L_{x}\left(w_{x} / L_{x}\right)\right)<(>) \mathrm{C} \\
& \tilde{a}_{22}=g_{L L}-\left(L_{x} /\left(\bar{L}-L_{y}\right)^{2}\right) w_{x}<0
\end{aligned}
$$

Stabilitv conditions are assumed to hold implying

$$
\left.\frac{d L_{y}}{d L_{x}}\right|_{x}=\frac{\tilde{1}_{11}}{-\sim_{12}}>\left.\frac{d L_{y}}{d L_{x}}\right|_{y}=\frac{\tilde{2}_{21}}{-{ }_{22}} \text { and }[\tilde{J}]>0 \text {. }
$$

In order to conduct comparative static exercises, four cases have to be distinguished since the signs of $\tilde{a}_{21}$ and $\tilde{a}_{12}$ are not determined. The signs for these different cases are summarized in proposition 3.

\section{Proof of Proposition 4:}

$\frac{d\left(w_{x} L_{x}\right)}{d K_{x}}=\frac{d w_{x}}{d L_{x}} L_{x}+\frac{d L_{x}}{d K_{x}} w_{x}=\frac{d w_{x}}{d L_{x}} \frac{d L_{x}}{d K_{x}} L_{x}+\frac{d L_{x}}{d K_{x}} w_{x}=\frac{d L_{x}}{d K_{x}}\left\lfloor\frac{w_{x}}{L_{x}} L_{x}+w_{x}\right\rceil$

but for ${ }_{x}>0,\left(\frac{w_{x}}{L_{x}} L_{x}+w_{x}\right)>0$.

Thus, $\operatorname{sign}\left(d\left(w_{i} L_{i}\right) / d j\right)=\operatorname{sign}\left(d L_{i} / d j\right)$ with $i=x, y$ and $j=K_{x}, K_{y}, \quad, p$. 
Proof of Proposition 5: Liberalizing Capital M ovements

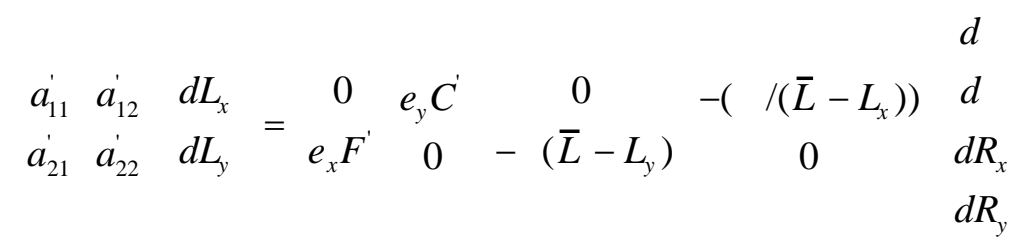

$$
\begin{aligned}
& C^{\prime}=\left(\left(g-R_{y}\right) /\left(L_{y}-g_{L}\right)<(>) 0\right. \\
& \left.F=\left(p f-R_{x}\right) / L_{x}-p f_{L}\right)<(>) 0
\end{aligned}
$$

The Jacobian is identical to [ $\tilde{\mathrm{J}}]$ except that the expressions for $\partial \mathrm{W}_{\mathrm{i}} / \partial \mathrm{L}_{\mathrm{i}}$ are different. Stability conditions will again be assumed to hold so that comparative statics results can be obtained. Only the new variables $R_{i}$ and the union bargaining strengths $\alpha$ and $\beta$ are considered because for all other variables the system is identical to the one derived in conjunction with the long-run equilibrium in proposition 3.

$$
\begin{aligned}
& \frac{w_{x}}{L_{x}}=\frac{-}{L_{x}}\left(p f_{L}-\frac{p f}{L_{x}}+R_{x}\right)+(1-) p f_{L L} \\
& \frac{w_{y}}{L_{y}}=\frac{-}{L_{y}}\left(g_{L}-\frac{g}{L_{y}}+R_{y}\right)+(1-) g_{L L}
\end{aligned}
$$

Necessary conditions for $\frac{w_{\mathrm{i}}}{L_{i}}<0$ are:

$$
\begin{aligned}
& R_{x}<p f_{K} K_{x}-(1-\quad) / p f_{L L} L_{x}^{2} \\
& R_{y}<g_{K} K_{y}-(1-\quad) / g_{L L} L_{y}^{2}
\end{aligned}
$$

These conditions will be assumed to hold in order to preserve a negative relationship between wages and employment. 